This item was submitted to Loughborough's Research Repository by the author.

Items in Figshare are protected by copyright, with all rights reserved, unless otherwise indicated.

\title{
Different ways to measure math anxiety
}

\section{PLEASE CITE THE PUBLISHED VERSION}

https://www.routledge.com/Mathematics-Anxiety-What-is-Known-and-What-is-still-to-be-

Understood/Mammarella-Caviola-Dowker/p/book/9780367190392

\section{PUBLISHER}

Taylor and Francis

\section{VERSION}

AM (Accepted Manuscript)

\section{PUBLISHER STATEMENT}

This is an Accepted Manuscript of a book chapter published by Routledge in Mathematics Anxiety: What Is Known and What Is Still to Be Understood on 26 February 2019, available online: http://www.routledge.com/9780367190330.

\section{LICENCE}

CC BY-NC-ND 4.0

\section{REPOSITORY RECORD}

Cipora, Krzysztof, Christina Artemenko, and Hans-Christoph Nuerk. 2019. "Different Ways to Measure Math Anxiety". Loughborough University. https://hdl.handle.net/2134/12210203.v1. 


\section{Chapter 2}

\section{Different ways to measure math anxiety}

Krzysztof Cipora*1,2, Christina Artemenko ${ }^{1,2}$, \& Hans-Christoph Nuerk ${ }^{1,2,3}$

${ }^{1}$ Department of Psychology, University of Tuebingen, Tuebingen, Germany

${ }^{2}$ LEAD Graduate School \& Research Network, University of Tuebingen, Tuebingen, Germany

${ }^{3}$ Leibnitz-Institut für Wissensmedien, Tuebingen, Germany

Cipora, K., Artemenko, C., \& Nuerk, H.-C. (2019). Different ways to measure math anxiety. In I.

Mammarella, S. Caviola, A. Dowker (Eds.), Mathematics Anxiety : what is known, and what is still missing. (pp. 20-41). New York, NY: Routledge.

* Corresponding author:

Dr. Krzysztof Cipora

Department of Psychology, University of Tuebingen,

Schleichstrasse 4, 72076 Tuebingen, Germany

e-mail: krzysztof.cipora@uni-tuebingen.de 


\section{General remarks}

Most of the objects we encounter on an everyday basis can be seen or touched. Therefore, we do not need specific measurement instruments to prove a specific object's existence and distinctiveness from other objects. Unfortunately, this is not the case for psychological constructs. They cannot be directly assessed via sensory experiences; they have to be indirectly assessed by specific measurement instruments. When attempting to measure psychological constructs one needs not only to show that the measurement is reliable, but also that the measurement of the construct is valid (e.g., by showing that different measurements of the same construct are related, and that measures of different constructs are not too strongly related). Math anxiety (MA) is such a psychological construct. Here, we provide an overview of the different ways to measure MA.

Before we are go into the details, we want to emphasize some basics about MA: MA can neither be reduced to poor math skill (i.e., one declares to be anxious about math solely because of having poor skills in this domain) nor to anxiety in general (i.e., one declares to be anxious about math solely because they are anxious about virtually everything). However, individual MA assessment is necessary for MA research, diagnosis, intervention planning and evaluation. In our overview of MA measurement instruments, we will focus mostly on self-descriptive measures, as they are the most popular methods. Additionally, we discuss other approaches for measuring MA including behavioral and (neuro)physiological measures. We will also point to some new avenues in MA measurement that should be considered in future investigations.

\section{Structure of math anxiety}

Despite more than fifty years of intense MA research, the question about its structure is far from being resolved. Discussing structure of MA thoroughly goes largely beyond the scope of this chapter. Nevertheless, we need to introduce the debate on that issue, because the postulated MA structure determines, to a certain extent, the way in which measurement instruments are built. As one can see in Table 1, subscales of the MA measurement instruments differ considerably. 
Usually it is claimed that MA comprises two factors: anxiety related to using math in everyday (learning) situations and anxiety related to being evaluated in math. This structure was proposed in early research, starting in the 1970s (see Suinn \& Edwards, 1982). Similarly, two factors (termed numerical anxiety and math test anxiety) account for the results of MARS - the first instrument aimed specifically at MA measurement (see below). A two-factor solution (Learning Math Anxiety and Math Evaluation Anxiety) was also found in its several revisions. These two factors are usually highly correlated (about .70; Hopko, 2003), and are also reflected in the Abbreviated Math Anxiety Scale (AMAS; Hopko, Mahadevan, Bare, \& Hunt, 2003; see below).

Nevertheless, there are some valid alternatives to the two-factorial solution. Several studies showed that MA comprises three components. For instance, three factors explain best the variance in sMARS scale (Alexander \& Martray, 1989). These factors are: (1) Math test anxiety, (2) Numerical Task Anxiety, and (3) Math Course Anxiety. Three factors also account best for the pattern of scores in the Mathematics Anxiety Scale - UK (MAS-UK) developed for the British population (Hunt, Clark-Carter, \& Sheffield, 2011). These factors were termed (1) Maths Evaluation Anxiety, (2) Everyday / Social Maths Anxiety, and (3) Maths Observation Anxiety. Furthermore, abstraction anxiety (anxiety related to abstract mathematical content) is also considered to be another MA component (Ma \& Xu, 2004). Some other researchers postulate that MA considers not only negative, but also positive affect towards math (e.g., Bai, 2011; Kazelskis, 1998).

Some recent studies suggest a more complex structure of MA. Based on Confirmatory Factor Analysis of MARS30-Brief scale, Pletzer, Wood, Scherndl, Kerschbaum, \& Nuerk (2016) concluded that a simple distinction between numerical anxiety and testing anxiety does not satisfactorily fit the data. Best fit was obtained by a model consisting of 6 factors: (1) Evaluation anxiety 1 proper - Taking math exam; (2) Evaluation anxiety 2 - Thinking of upcoming exam; (3) Learning math anxiety; (4) Everyday numerical anxiety; (5) Performance anxiety; (6) Social responsibility anxiety. Another recent study (Yánez-Marquina \& Villardón-Gallego, 2017) showed that MA is as a hierarchical construct. Firstly, two general factors of Everyday life math anxiety and Academic math anxiety were 
differentiated. The latter was further subdivided into Math learning anxiety and Math test anxiety. This new model is theoretically interesting as it includes both MA related to academic and everyday life situations, however, it requires further investigation.

The models discussed above tried to capture MA related to different contexts and situations. Nevertheless, they treated anxiety as being perceived as unitary in each of these contexts and situations. Another approach differentiates two MA dimensions even within a context: an affective and a cognitive one. The affective dimension refers to feelings of nervousness, dread etc., while the cognitive dimension refers to the worry component of anxiety (Ho et al., 2000). It is worth noting that this MA framework corresponds well to the understanding of anxiety and its influence on cognition in general (see Calvo \& Eysenck, 1992).

There is much less evidence on MA structure in children of early school age. For a long time it was assumed that MA develops only around $6^{\text {th }}$ grade when negative experiences with math accumulate and the math content becomes more difficult. However, more recent studies show that MA is present much earlier, and can be accurately measured even at the onset of school age (see Harari, Vukovic, \& Bailey, 2013; Krinzinger, Kaufmann, \& Willmes, 2009). Nevertheless some studies suggest componential MA structure in these early ages such as (a) math learning and (b) math evaluation anxiety (Carey, Hill, Devine, \& Szúcs, 2017) or (a) negative emotions; (b) numerical confidence; (c) worry (Harari et al., 2013).

In sum, the factorial structure of math anxiety remains relatively unclear and different structural proposals currently exist in the literature, however, most researchers agree that it is not a unidimensional construct. The variety of models of MA structure requires researchers to carefully select the measurement instruments, so that they meet their particular needs. On the other hand, one must keep in mind that the selection of a particular instrument automatically restricts theoretical claims and possibilities for differential diagnosis and tailored intervention. 


\section{Paper-and-pencil self-descriptive math anxiety measurement instruments}

Measuring math anxiety in adults and adolescents

MA questionnaires have been developed since the 1960s. Ashcraft and Moore (2009) briefly

summarize the history of MA measurement (see also Eden, Heine, \& Jacobs, 2013; Yánez-Marquina \& Villardón-Gallego, 2017 for overviews of different instruments). The first instrument used for measuring MA was a modification of Taylor Manifest Anxiety Scale proposed by Dreger and Aiken (1957), who introduced three specific MA items to that scale.

The Mathematics Anxiety Rating Scale (MARS; Richardson \& Suinn, 1972) was the first tool specifically designed to measure math anxiety. It comprises 98 items and is characterized by satisfactory psychometric properties. It covers both everyday life situations as well as academic settings. However, the large number of items makes its administration rather time consuming. Numerous modifications of the MARS have aimed at shortening the scale without loss of psychometric quality. For instance, MARS-R (standing for MARS-Revised; Plake \& Parker, 1982) comprises only 24 items. It is characterized by very good psychometric properties and strongly correlates with the original MARS (.97). It comprises a composite score and two subscale scores for Learning Math Anxiety and Math Evaluation Anxiety. Subsequent confirmatory factor analysis of MARS-R items by Hopko (2003) suggested further shortening it to 12 items without loss in psychometric properties. Another very popular tool is called sMARS (standing for shortened MARS; Alexander \& Martray, 1989), a 25-item scale which highly correlates (.97) with the MARS. It is also characterized by excellent psychometric properties. This scale is the most popular among MA researchers.

Numerous instruments originating either directly or indirectly from MARS got very popular and for a long time were utilized in the vast majority of MA studies. They are all characterized by very good psychometric properties and are well established in the field. Nevertheless, they are all copyrighted 
and cannot be used free of charge either for research purposes or for diagnosis. As an alternative, numerous freely available instruments were developed. Their psychometric properties are also very good, and they are gaining more and more popularity (see Table 1 for overview of such instruments). Interestingly, as Ashcraft (2002) notes, participants' answer to the single question about his or her math anxiety on a 10-point scale correlates from .49 up to .85 with the sMARS score. Very good validity and reliability of a single item scale (termed Single-Item Math Anxiety Scale - SIMA) was also shown in a subsequent systematic study. Participants are required to give an answer to the following question: “On a scale from 1 to 10, how math anxious are you?” (Núñez-Peña, Guilera, \& SuárezPellicioni, 2014). It is worth noting that a similar single question approach was chosen to assess math anxiety in the PISA studies (see Lee, 2009; OECD, 2013). However, while the correlations with some overall math anxiety questionnaires is high, the SIMA only allows for a general assessment of MA level, but no differential diagnosis, which context and situations are affected (e.g., whether MA equally strongly affects everyday situations and being tested in math). Therefore, such extremely short instruments might be used as a general measure for an unstructured covariate math anxiety, but it is not suitable for differential diagnostics and adequate, tailored intervention planning. In general, most MA instruments are characterized by very good psychometric properties. The selection of a MA questionnaire for a particular research purpose should also be guided by the research questions, especially whether one wishes to tap only a very general MA level, or rather relations to specific MA components are expected, and the sample to be targeted.

Table 1. Examples of freely available MA measurement instruments

$\begin{array}{llll}\text { Abbreviation Full name } & \begin{array}{l}\text { No. Subscales } \\ \text { of } \\ \text { items }\end{array} & \begin{array}{l}\text { Target } \\ \text { group }\end{array} & \text { Reference } \\ & & \end{array}$

\begin{tabular}{|c|c|c|c|c|c|}
\hline \multicolumn{6}{|c|}{ Measures aimed for adults and adolescents } \\
\hline AMAS & $\begin{array}{l}\text { Abbreviated } \\
\text { Math Anxiety } \\
\text { Scale }\end{array}$ & 9 & $\begin{array}{l}\text { - Total score } \\
\text { - Learning subscale } \\
\text { - Testing subscale }\end{array}$ & $\begin{array}{l}\text { Adults and } \\
\text { adolescents, } \\
\text { in some } \\
\text { studies from } \\
\text { 8-year-olds }\end{array}$ & $\begin{array}{l}\text { Hopko et } \\
\text { al. (2003) }\end{array}$ \\
\hline MAS-UK & $\begin{array}{l}\text { Math anxiety } \\
\text { scale - UK }\end{array}$ & 23 & $\begin{array}{l}\text { - Total score } \\
\text { - Maths evaluation }\end{array}$ & Adults & $\begin{array}{l}\text { Hunt et al. } \\
\text { (2011) }\end{array}$ \\
\hline
\end{tabular}




\begin{tabular}{|c|c|c|c|c|c|}
\hline & & & $\begin{array}{l}\text { anxiety } \\
\text { - Everyday / social } \\
\text { maths anxiety } \\
\text { - Maths observation } \\
\text { anxiety }\end{array}$ & & \\
\hline SIMA & $\begin{array}{l}\text { Single-Item Math } \\
\text { Anxiety Scale }\end{array}$ & 1 & NA & $\begin{array}{l}\text { Adults and } \\
\text { adolescents }\end{array}$ & $\begin{array}{l}\text { Núñez- } \\
\text { Peña et al. } \\
\text { (2014) }\end{array}$ \\
\hline \multicolumn{6}{|c|}{ Measures aimed for adolescents and children } \\
\hline CAMS & $\begin{array}{l}\text { Children's } \\
\text { anxiety in math } \\
\text { scale }\end{array}$ & 16 & $\begin{array}{l}\text { - Total score } \\
\text { - General math anxiety } \\
\text { - Math performance } \\
\text { anxiety } \\
\text { - Math error anxiety }\end{array}$ & $\begin{array}{l}\text { Grades 1-5 } \\
\text { (no age } \\
\text { reported) }\end{array}$ & $\begin{array}{l}\text { Jameson } \\
\text { (2013) }\end{array}$ \\
\hline CMAQ & $\begin{array}{l}\text { Child Math } \\
\text { Anxiety } \\
\text { Questionnaire }\end{array}$ & 8 & - Total score & 7-year-olds & $\begin{array}{l}\text { Ramirez et } \\
\text { al. (2013) }\end{array}$ \\
\hline FSMAS-SF & $\begin{array}{l}\text { The Fennema- } \\
\text { Sherman } \\
\text { Mathematics } \\
\text { Attitudes Scales } \\
\text { - Short Form }\end{array}$ & 51 & $\begin{array}{l}\text { - Total score } \\
\text { - Attitude Towards } \\
\text { Success in } \\
\text { Mathematics } \\
\text { - Mathematics as a } \\
\text { Male Domain } \\
\text { - Parent's Attitudes } \\
\text { - Teacher's Attitudes } \\
\text { - Mathematics-Related } \\
\text { Affect } \\
\text { - Usefulness of } \\
\text { Mathematics }\end{array}$ & $\begin{array}{l}\text { Two age } \\
\text { groups: 12- } \\
\text { year-olds, 15- } \\
\text { year-olds }\end{array}$ & $\begin{array}{l}\text { Mulhern } \\
\text { \& Rae } \\
(1998)\end{array}$ \\
\hline mAMAS & $\begin{array}{l}\text { Modified } \\
\text { Abbreviated } \\
\text { Math Anxiety } \\
\text { Scale }\end{array}$ & 9 & $\begin{array}{l}\text { - Total score } \\
\text { - Math evaluation } \\
\text { subscale } \\
\text { - Math learning } \\
\text { subscale }\end{array}$ & $\begin{array}{l}\text { Validated in } \\
\text { one age } \\
\text { group: 8-13 } \\
\text { year-olds }\end{array}$ & $\begin{array}{l}\text { Carey et } \\
\text { al. (2017) }\end{array}$ \\
\hline MAQ & $\begin{array}{l}\text { Math Anxiety } \\
\text { Questionnaire }^{1}\end{array}$ & 11 & $\begin{array}{l}\text { - Negative affective } \\
\text { reactions } \\
\text { - Worry }\end{array}$ & $\begin{array}{l}\text { Grades 5-11 } \\
\text { (no age } \\
\text { reported) } \\
\end{array}$ & $\begin{array}{l}\text { Wigfield \& } \\
\text { Meece } \\
\text { (1988) }\end{array}$ \\
\hline MAS-R & $\begin{array}{l}\text { Mathematics } \\
\text { Anxiety Scale - } \\
\text { Revised }\end{array}$ & 14 & $\begin{array}{l}\text { - Negative affect } \\
\text { towards math } \\
\text { - Positive affect } \\
\text { towards math }\end{array}$ & Grades 7-8 & Bai (2011) \\
\hline SAMAS & $\begin{array}{l}\text { Scale for } \\
\text { Assessing Math } \\
\text { Anxiety } \\
\text { in Secondary } \\
\text { education }\end{array}$ & 25 & $\begin{array}{l}\text { - Total score } \\
\text { - Everyday life's math } \\
\text { anxiety } \\
\text { - Academic math } \\
\text { anxiety } \\
\text { - Math learning } \\
\text { anxiety } \\
\text { - Math test anxiety }\end{array}$ & $\begin{array}{l}\text { Validated in } \\
\text { one age } \\
\text { group: } 12-16 \\
\text { year-olds }\end{array}$ & $\begin{array}{l}\text { Yánez- } \\
\text { Marquina } \\
\text { et al. } \\
\text { (2017) }\end{array}$ \\
\hline
\end{tabular}

\footnotetext{
${ }^{1}$ Note that another questionnaire with the same name was developed by Thomas and Dowker
} (2000). 


\begin{tabular}{|c|c|c|c|c|c|}
\hline SEMA & $\begin{array}{l}\text { Scale for Early } \\
\text { Mathematics } \\
\text { Anxiety }\end{array}$ & 20 & $\begin{array}{l}\text { - Total score } \\
\text { - Numerical processing } \\
\text { Anxiety } \\
\text { - Situational and } \\
\text { Performance Anxiety }\end{array}$ & 8-year-olds & $\begin{array}{l}\text { Wu et al. } \\
\text { (2012) }\end{array}$ \\
\hline- & $\begin{array}{l}\text { Mathematics } \\
\text { Anxiety Scale for } \\
\text { Young Children }\end{array}$ & 12 & $\begin{array}{l}\text { - Total score } \\
\text { - Negative reactions } \\
\text { - Numerical confidence } \\
\text { - Worry }\end{array}$ & $\begin{array}{l}\text { 6-7 year } \\
\text { olds }\end{array}$ & $\begin{array}{l}\text { Harari et } \\
\text { al. (2013) }\end{array}$ \\
\hline
\end{tabular}

\section{The Abbreviated Math Anxiety Scale (AMAS)}

Nowadays, one of the most commonly used math anxiety measures is the AMAS, standing for Abbreviated Math Anxiety Scale (Hopko, Mahadevan, et al., 2003). Due to its popularity and potential for being utilized in numerous linguistic and cultural contexts, varied age groups, and administration modes, we describe it in more detail in following paragraphs.

AMAS comprises nine items contributing to two scales: Math Learning and Math Testing, moreover, overall sum score is calculated. AMAS originates from a reanalysis of a MARS-R by Hopko (2003). The widespread use of AMAS is possibly due to its very short form (administration takes no more than 5 minutes), and to its very good psychometric properties: high reliability as measured by internal consistency and test-retest method, construct validity as measured by exploratory and confirmatory factor analyses, as well as convergent and discriminant validity (Hopko, Mahadevan, et al., 2003). Numerous subsequent studies have confirmed these results (see Cipora, Willmes, Szwarc, \& Nuerk, 2017 for a summary).

Crucially, good psychometric properties of the AMAS were shown in varied cultural and linguistic contexts: (1) American (e.g., Ferguson, Maloney, Fugelsang, \& Risko, 2015; Hopko, Mahadevan, et al., 2003); (2) Iranian (Vahedi \& Farrokhi, 2011); (3) Spanish (Brown \& Sifuentes, 2016); (4) Italian (Caviola, Primi, Chiesi, \& Mammarella, 2017; Primi, Busdraghi, Tomasetto, Morsanyi, \& Chiesi, 2014); (5) German (Dietrich, Huber, Moeller, \& Klein, 2015; Schillinger, Vogel, Diedrich, \& Grabner, 2018, and also yet unpublished studies conducted in our lab); (6) Polish (Cipora, Szczygiel, Willmes, \& 
Nuerk, 2015; Cipora et al., 2017). AMAS has also been translated into other languages such as French, Chinese, and Russian.

Another advantage of the AMAS is that it can be administered to a variety of age groups. It seems to work well with adolescents at the high school level. There are also some studies showing its suitability for MA measurement even with younger individuals. For instance, it was successfully administered to 11-year-olds (Devine, Fawcett, Szűcs, \& Dowker, 2012). In a modified form (mAMAS, Carey, Hill, et al., 2017), it was even used to measure MA of 8-13-year-olds.

Its short form and easiness of administration makes AMAS a perfect instrument for online administration (see Reips, 2002 for guidelines for online testing). AMAS has been administered online in several studies (see e.g., Ferguson et al., 2015; Jones, Childers, \& Jiang, 2012). A systematic study by Cipora and colleagues (2017) has shown equivalence of the online administration mode to the traditional paper-pencil version. The only caveat was that mean scores were lower in the case of online administration, however effect sizes related to these differences were small ( $d s \leq 0.16)$. This finding is partly at odds with early observations that MA scores are higher when administered via a computer (Ashcraft \& Faust, 1994). This discrepancy may be related to the fact that when the study by Ashcraft and Faust (1994) was conducted, computers were not as accessible as they are nowadays and using them required much more technical knowledge than it does now.

\section{Questionnaires for math anxiety in children}

Most of the instruments aimed at MA measurement for adults can also be used with adolescents. However, there are measures specifically designed for kids and adolescents. The first of them was MARS-A (Suinn \& Edwards, 1982) aimed at MA measurement in adolescents. A 26-item MARS-E (Suinn, Taylor, \& Edwards, 1988) was developed for younger children, specifically grades 5-6.

When it comes to younger children it was argued that one cannot differentiate MA from other anxiety types and that MA does not correlate with math performance at this stage of development. However, subsequent studies have shown, that MA can be reliably measured even at the beginning 
of elementary school (see Krinzinger et al., 2009 for an overview of the debate). Furthermore, it was also shown that MA affects performance even in the early years of education (Harari et al., 2013; Ramirez et al., 2013). Nevertheless, one needs to obey some caveats, when math anxiety of very young children (e.g, first grade) is measured. First, not all of them might have the necessary selfinspection needed for self-rating questionnaires. Second, reading skill and linguistic comprehension is limited. Not all questions might be well understood, especially when given in written format. Thirdly, there is, of course, the general problem with children of that age not always being motivated in assessments. This is a problem for performance tests, but inadequate responses can also be a problem in personality and other self-descriptive questionnaires.

Nevertheless, MA measurement seems to be possible and needed also in early grades, but such results have to be interpreted with care, especially, when it comes to individual diagnosis.

Luckily, several psychometrically evaluated instruments allowing such measurements are available (cf. Table 1). When constructing these instruments, several means were taken to make instruments suitable for administration to children, such as (a) minimizing number of items; (b) shortening the response scale, and replacing numbers with emotional expressions (e.g., of cartoon characters) depicting increasing worry; (d) decreasing dependency on the reading skills by reading the items aloud to the children (see e.g., Harari et al., 2013).

\section{Conclusions}

To conclude, in recent years one could observe two opposing trends in MA measurement. Firstly, there was a tendency to develop and use instruments need least time to administer, such as, for instance, the AMAS (Hopko, Mahadevan, et al., 2003) or SIMA (Núñez-Peña et al., 2014). Short administration time and very good psychometric properties are undisputable advantages of these instruments. On the other hand, for obvious reasons such instruments consider very few (if any) MA subcomponents. Therefore, the risk of using them and skipping more multi-factorial instruments is that developments in understanding MA will be biased towards a simplified picture of the construct, which is both theoretically problematic, but also practically for diagnosis and interventions. The other 
quite recent trend is the development of instruments allowing the measurement of more finegrained MA components (e.g., Pletzer et al., 2016) or postulating a hierarchical structure of MA (Yánez-Marquina \& Villardón-Gallego, 2017).

It seems that both trends might lead to valuable insights into the nature and consequences of MA. The first one seems to be very valuable in context of incorporating MA as a potential measure of interest in a broad range of numerical cognition research. It might facilitate tracing cognitive mechanisms of MA as well as lead to better understanding of elementary numerical processing itself (see e.g., Georges, Hoffmann, \& Schiltz, 2016 for an evidence that MA influences elementary number processing). Developing such tools will also simplify screening students for elevated MA levels. On the other hand, the development of more fine-grained instruments will be particularly helpful for individual diagnosis and intervention planning, especially for individuals who were initially diagnosed with elevated MA level using a more general instrument.

Undoubtedly, self-descriptive tools are most popular means of MA measurement. Recent research has also shown that MA can be effectively measured even at the onset of schooling. Nevertheless, there are also other types of measures, which do not rely on self-report but also have been successfully utilized for MA measurement, and they address some disadvantages of self-descriptive measures.

\section{Behavioral, physiological, and neuroscientific methods}

Self-reports in personality psychology like the above-mentioned math anxiety questionnaires have their problems - as shortly outlined below.

- They require functioning self-inspection and can therefore be problematic with children and patient groups.

- They require good reading skill and thorough linguistic understanding and can therefore be problematic with children and adults who are functionally illiterate. 
- They can be manipulated consciously like in selection situations, but also unconsciously (social desirability effects).

Often self-report measures correlate poorly with other measures, like ratings by another person or physiological and neuroscientific variables. Such poor correlations can be due to error variance in either variable, but most likely, they are due to flaws in both variables. In a more theoretical framing, one could say that there is no perfect method of assessment of the underlying construct of MA. Therefore, it is worthwhile to view different methods of assessment as complimentary approaches to uncover as much as possible about MA. For this reason, we wish to give an overview of other behavioral, physiological and neuroscientific correlates of MA that can potentially serve as MA measures in the future.

There were several attempts to measure MA by using behavioral, physiological and neuroscientific methods. Due to the large variety of these methods, however, there is a lack of systematics in the investigation of MA by these methods, none of them are as well-established as the self-report-based questionnaires for MA, and usually they are not considered as a substitute for, but rather a complement to, the use of questionnaires.

Regarding behavioral measures, the most prominent are reaction time (RT) and accuracy (ACC) assessments during math tasks or when handling math related material. Interestingly, the relation of speed and accuracy is dependent on the level of math anxiety (Ashcraft \& Faust, 1994): individuals with low MA show a fast RT and high ACC, individuals with medium MA show slow RT (with relatively high ACC), and individuals with high MA show low ACC (with relatively fast RT). Future studies should explore whether specific strategies in terms of speed and accuracy trade-off (e.g., much above average speed and much below average accuracy) can be a valid measure of an individual's MA. Another possible way to measure MA with RT methods are interference effects. For instance, it was shown that individuals with high MA reveal stronger interference effects when they are to inhibit task irrelevant numerical information (Hopko, McNeil, Gleason, \& Rabalais, 2002). 
As MA is separate from math skill, typical math performance tasks cannot be used as a MA measure. However, as it was shown influence of MA on math performance depends on conditions, for instance it increases with time pressure (see Ashcraft \& Moore, 2009). Once all individuals can master some easy problems when tested in a relaxed and untimed condition (Faust, Ashcraft, \& Fleck, 1996), introducing time pressure leads to an affective drop in performance for individuals with medium or high MA (see Ashcraft \& Moore, 2009). For this reason, future studies can explore whether discrepancy between performance in stressful and non-stressful conditions can be considered as a valid measure of individual MA level.

Further interesting approaches might be taken from the field of stress research, since the reaction of math-anxious individuals to math-related situations also includes a stress reaction. Therefore, measures of cortisol secretion (e.g., Mattarella-Micke, Mateo, Kozak, Foster, \& Beilock, 2011; Pletzer, Wood, Moeller, Nuerk, \& Kerschbaum, 2010; Sarkar, Dowker, \& Cohen Kadosh, 2014) and postural control (e.g., Doumas, Morsanyi, \& Young, 2018) are of use in MA research.

Regarding physiological measures, especially methods from the context of emotion processing have been also applied in MA research. In particular, heart rate (ECG) and blood pressure as well as skin conductance (EDA) and temperature might be associated with the increased arousal during a math task caused by math anxiety (e.g., Dew, Galassi, \& Galassi, 1984; Hopko, McNeil, et al., 2003; Osborne, 2006; Salvia et al., 2013). However, up-to-date evidence for psychophysiological markers of math anxiety is rather small and requires more research in the future.

Regarding neuroscientific methods, several neuroimaging, neurophysiological and brain stimulation methods have been used to investigate the neural correlates of MA (see Artemenko, Daroczy, \& Nuerk, 2015 for an overview). By using (functional) magnetic resonance imaging (MRI/fMRI), altered activation patterns before and during math tasks (e.g., Lyons \& Beilock, 2012a, 2012b; Pizzie \& Kraemer, 2017), altered functional connectivity (Young, Wu, \& Menon, 2012), altered default mode network deactivation (Pletzer, Kronbichler, Nuerk, \& Kerschbaum, 2015), and altered structural correlates (Hartwright et al., 2018) were detected related to MA. Furthermore, studies using 
electroencephalography (EEG) detected differences in event-related potentials (ERP) (e.g., Klados, Simos, Micheloyannis, Margulies, \& Bamidis, 2015; Núñez-Peña \& Suárez-Pellicioni, 2014; SuárezPellicioni, Núñez-Peña, \& Colomé, 2013a, 2013b, 2014) and brain oscillations (Klados, Pandria, Micheloyannis, Margulies, \& Bamidis, 2017) between individuals with high and low MA. For instance, the neural signature of standard numerical effects, such as the distance effect and the size effect, were shown to differ due to MA (Núñez-Peña \& Suárez-Pellicioni, 2014). Finally, one single study (Sarkar et al., 2014) aimed at intervening in the math performance deficit of individuals with high MA by using non-invasive brain stimulation. Thereby, they applied transcranial direct current stimulation (tDCS) over a brain region responsible for emotion regulation and were able to reduce the cortisol level, indicating the stress level, and to improve the math performance of math-anxious individuals (Sarkar et al., 2014 see also Lyons \& Beilock, 2012a).

Taken together, behavioral, psychophysiological and neurophysiological methods can be successfully used to detect differences in neural processing between individuals with high and low MA and to provide interventional approaches on a physiological level. However, due to the diversity of the methods, analyses, and results in these studies and the exclusively conducted analyses on a group level, individual diagnosis of MA is (still) out of the scope for these measures (Artemenko et al., 2015). Therefore, we recommend more systematic research on the diagnostic usefulness of the physiological markers of MA in future. It is possible that such measures can provide complimentary evidence to self-descriptive reports.

\section{Challenges and unanswered questions}

\section{Who is math anxious?}

One might ask how many people are math anxious. The issue of MA prevalence is vital for curricula development, policy making, and intervention planning. However, there is no consensus on the issue so far. As always in psychological research, we are looking at a continuously distributed variable without visible gap between two dichotomous groups (like with many medical diseases, which one 
might have or not have). The inspection of results of large scale studies shows that the distributions of MA scores represent a normal rather than a bimodal distribution (Cipora et al., 2015, Fig. 1, 2017, Fig. 1). For this reason, MA should be considered as a continuous, not a binary trait. One pole of this continuum would represent extreme anxiety towards math. While MA level gets lower along this continuum, it still exists. Sometimes it is even claimed that the majority of the population might encounter some negative feelings related to math (see Chang \& Beilock, 2016). As a side note we can add that it is not agreed on what represents the positive pole - being neutral towards math, or rather positive affective responses towards math and solving math problems (e.g., of a relaxation see Sacks, 1985, especially the chapter "The Twins"). As for all non-dichotomous variables, the MA prevalence depends on the criterion adopted - these criteria differ between studies and organizations and therefore prevalence estimates can also differ greatly.

MA is not considered in existing medical classifications such as DSM-5 or ICD-10. There are no strict, agreed upon diagnostic criteria for MA. Some researchers provide estimates of MA prevalence based on results of the PISA (Programme for International Student Assessment) study (e.g., Morsanyi et al., 2016). For instance, estimates of prevalence based on this data are around $30 \%$ for the proportion of individuals who (strongly) agree with the statement that they "get very nervous doing mathematics problems" (see OECD, 2013, p. 99). A bit lower prevalence estimates appeared in early studies: Richardson and Suinn (1972) have suggested that in about $11 \%$ of the university student population's MA is high enough that they would need counselling. Further estimates seem to be similar, however, one must keep in mind that usually all these estimates were at least to some extent based on statistical criteria, such as top $\mathrm{x} \%$ (e.g., $10 \%$ like the ICD often uses) of a population or above $\mathrm{n} S D \mathrm{~s}$ from population mean (see Dowker, Sarkar, \& Looi, 2016 for a recent summary).

When investigating the relation of MA to math performance, the problem of defining high vs. low MA groups was permanently present in basic research. Ashcraft and Ridley (2005) summarize that usually groups were composed based on a median split or selection of extreme groups (e.g., $20 \% / 25 \%$ scoring lowest vs. $20 \% / 25 \%$ scoring highest) from a pool of initially screened participants. 
The latter method, assuming sufficient variance in the sample and a reliable MA measurement, is especially adequate for basic research. However, the absolute values of the cut-off criteria depend solely on characteristics of the sample being tested in the particular experiment. For this reason, the results of different experiments can be hardly comparable. In extreme cases, a particular score might be assigned either to the low or to the high MA group depending on the sample being screened. Furthermore, despite some usefulness in basic research, such a relative approach does not allow for estimating the prevalence of MA. This is because classifying a given percentage of participants as math anxious is an arbitrary decision of the researcher. Additionally, it does not allow interpretation of individual scores for diagnostic purposes.

Based on the above discussion one can see that prevalence and individual diagnostic cut-offs of MA are still far from being resolved. As argued by Ashcraft and Ridley (2005), MA meets the criteria for a genuine phobia, so in the long run it might be possible to adapt the diagnostic criteria for a specific phobia for MA diagnosis. Based on such somehow objectivized criteria (e.g., degree to which MA affects well-being in academic setting, or how much it influences one's life or career choices), one could estimate MA prevalence and allow for the individual diagnosis. However, as MA seems to be continuous trait, individual diagnosis could also be based on normative data reflecting MA levels in the population. Having established valid and reliable MA measurement instruments, the next step for their practical usefulness is therefore constructing norms. Creating norms for widely used MA instruments would be possible, for instance, by collapsing existing datasets of individual scores, and building norms based on these numerous samples. Using these norms (adjusted to a given linguistic and cultural context) as a reference can turn out to be useful in basic research; researchers can ensure that samples are comparable between studies in regards to MA. It will be also helpful for diagnostics and intervention planning. Such efforts have been already made for the AMAS (see e.g., Caviola et al., 2017; Cipora et al., 2017), SEMA (Wu et al., 2012), or the German version of the MAQ (Krinzinger et al., 2007). 


\section{Are we always math anxious?}

One of the most important distinctions in anxiety research is the differentiation between trait and state anxiety, first introduced by Spielberger (see Endler \& Kocovski, 2001 for a discussion). While trait anxiety is considered as a stable disposition to respond with anxiety to a wide range of situations, state anxiety refers to feelings being related to particular circumstances. New developments in the field of MA suggest that this differentiation seems to be valid also for MA. Several studies show discrepancies between state and trait MA (Bieg, Goetz, Wolter, \& Hall, 2015; Roos et al., 2015). This means that MA differs not only between individuals but also between situations. For example, we have recently observed that state anxiety changes depending on the difficulty of arithmetic problems individuals are to solve.

In sum, the accumulating body of research shows that it is worthwhile to consider both the trait and state aspects related to MA in the case of basic research and for individual diagnosis. At best, a psychometrically evaluated, freely available measurement instrument considering the state aspects of MA needs to be introduced, or at least adapted from state anxiety scales, and evaluated in different cultural and linguistic contexts.

\section{A broader perspective on math anxiety measurement and its practical usefulness}

As discussed above, MA in principle can be measured reliably and validly in various populations, cultures, and by different kinds of measures. Undoubtedly, this fact is theoretically sound and it proves the existence of MA as a construct being distinct from poor math skill and from general trait anxiety. The link between MA and math performance has been shown in numerous countries and cultures (see Foley et al., 2017 for a review). However, an increasing body of evidence points out that not only MA level, but also specific configurations of other traits play a role in the relation between MA and math performance. These observations set new challenges for MA measurement because elevated MA level might potentially have different consequences in different individuals. 
In a study conducted in Poland with a group of adult university students of different faculties, Cipora and colleagues (2015) expectedly found a correlation between MA and self-assessed math skill, school math grades, and liking of math and sciences. MA further correlated with persistence in attempting to solve math problems and being likely to use non-allowed help when struggling with math problems. MA also correlated with trait and state anxiety. The size of these correlations was similar to the correlations reported in other published studies. However, when the sample was split depending on field of study into two groups studying math-related (e.g., math, physics, economics, engineering) or math-unrelated subjects (e.g., literature, pedagogy), it turned out that the pattern of correlations differed considerably between groups. Specifically, MA correlated with self-assessed math skill, math grades, persistence in solving math problems and liking of math only for individuals who studied math-unrelated subjects, while such a relation was not present for students of mathrelated subjects. This was not due to floor or ceiling effects in any of the variables. Importantly, in the math-related group MA correlated with state and trait anxiety. Similar results were found in two follow-up studies conducted in our lab. When interpreting these results, one must keep in mind that field of study selection can be influenced not only by skills but also interests, attitudes, and potentially - MA. For instance, one can observe that individuals characterized by relatively high MA, who still selected study math-related subjects do not perform worse than those characterized with lower MA. For this reason, such a difference in correlation patterns requires a more thorough investigation.

In recent years, several studies have suggested that the correlation between MA and math performance can be moderated by several constructs. We will briefly describe some of them:

1. Self-math overlap is the extent, to which one incorporates math into the structure of his/her self (Necka, Sokolowski, \& Lyons, 2015). Across participants who declared high self-math overlap the correlation between MA and math performance was smaller than in those who characterized themselves with low overlap. 
2. Math motivation (Wang et al., 2015). Uniform linear relationship was only observed in individuals characterized by low intrinsic math motivation. On the other hand, for those characterized by high intrinsic motivation there was inverted U-relation between MA and math performance: math performance was highest in moderately anxious individuals.

3. Math self-concept (Justicia-Galiano, Martín-Puga, Linares, \& Pelegrina, 2017). MA - math performance relationship in children was mediated by working memory capacity and math self-concept.

Another line of evidence that the relationship between MA and math performance is not unitary across individuals comes from studies utilizing a method called Latent Profile Analysis (LPA). It allows detection of the configurations of multiple traits (see Hickendorff, Edelsbrunner, McMullen, Schneider, \& Trezise, 2018 for examples of use in differential psychology). Specifically, it allows one to look at individual differences not only in terms of traits, but also in terms of their specific configurations. Below we list some of these findings:

1. Carey, Devine, Hill, and Szúcs (2017) differentiated four different latent profiles depending on MA, test anxiety, and general anxiety. The link between MA and math performance was more pronounced in individuals characterized by the so-called "academic anxiety" profile (elevated MA and test anxiety), than in individuals characterized by the so-called "high anxiety" profile (elevated all anxiety types).

2. Hart et al. (2015) differentiated five latent classes based on configurations of MA, and different measures of math performance. None of the groups was found to be above average both in math performance and MA.

3. Mammarella, Donolato, Caviola, and Giofrè (2018) found different anxiety profiles in grades 3 to 6 . However, contrary to the findings from Carey et al. (2017), the profiles were not characterized by dissociations between levels of different anxiety types.

4. Trezise and Reeve (2018) indicate stability in currently perceived anxiety depending on task difficulty as one of distinctive features of profiles they differentiated: interestingly only two 
out of five profiles (very high and very low MA) were consistent across types of tasks. Three other profiles revealed fluctuations in MA depending on task difficulty, way of presenting a problem, and presence of time pressure.

5. Wang, Shakeshaft, Schofield, and Malanchini (2018) show that individuals of the same MA level but differing in certain aspects of math motivation can differ considerably in their math performance.

The studies discussed above provide evidence that adequate MA measurement requires looking at more than MA levels. To obtain sufficient prognostic validity (i.e., being able to predict math performance based on MA level) one needs to consider MA in the context of other individual characteristics. A full list of these characteristics still needs to be established.

It must be noted that all of these developments are relatively recent and some work still needs to be done to translate them into practice and to implement them into commonly used measurement instruments. Potentially, a standardized battery of tests measuring different anxiety types, all using the same standardized scale could be prepared. Using such an unified battery would allow for calculation of critical differences so that one could check whether standard scores differ significantly between tests (see Cipora et al., 2017 for an example). Such a differential profile could potentially serve as a proxy for individual anxiety profiles and could be used for diagnostic purposes, as well as for tailoring interventions. These results also suggest that when designing interventions, one should also target some potential mediators of the MA - math performance relationship. However, the feasibility and validity of such approaches still needs to be investigated. Nevertheless, we consider development of a diagnosis of MA which would also consider other relevant constructs as one of biggest challenges of MA measurement. This entirely new avenue of research needs to take developmental aspects into consideration, as in early school years MA and general math anxiety are less differentiated (or at least can be assessed as such) and the added value of using latent profiles seems to be limited in this age group (Mammarella et al., 2018). Furthermore, recent results suggest 
that considering different anxiety profiles can also inform studies on the state-trait distinction of MA (Trezise \& Reeve, 2018).

\section{Concluding remarks}

Here we provided an overview of MA measurement techniques, spreading from traditional selfdescriptive questionnaires to their computerized implementations, as well as behavioral and (neuro)physiological measures. A review of the literature shows that all these methods can be used to reliably and validly measure MA in most populations. In other words, it suggests that a reliable and valid indicator of general MA is relatively simple (e.g., by directly asking a single question on whether one is afraid of math). However, such an indicator falls short of capturing the heterogeneity of the math anxiety construct, it is not useful for differential individual diagnosis and tailored adaptive intervention planning. For instance, if a child has only math test anxiety, but no math anxiety in everyday math situations, it would be probably a waste of resources to tackle everyday math situations.

What still needs to be done, both to improve the understanding of MA and implementing these developments in practice, is making the research instruments, especially freely available ones, suited to individual diagnostic purposes by preparing norms. Furthermore, tracing the temporal dynamics of MA, considering situational factors can be insightful both for basic research, and for the utility of individual diagnostics. Finally, one of the biggest upcoming challenges is adequate MA measurement in a context other constructs potentially influencing its relationship with math skill.

\section{Acknowledgments}

KC is supported by a DFG grant [NU 265/3-1] to HCN. KC, CA, and HCN are further supported by the LEAD Graduate School \& Research Network [GSC1028], which is funded within the framework of the Excellence Initiative of the German federal and state governments. We thank Zoë Kirste for proofreading the manuscript. 


\section{References}

Alexander, L., \& Martray, C. (1989). The Development of an Abbreviated Version of the Mathematics Anxiety Rating Scale. Measurement and Evaluation in Counseling and Development, 22(3), 143150. https://doi.org/10.1080/07481756.1989.12022923

Artemenko, C., Daroczy, G., \& Nuerk, H.-C. (2015). Neural correlates of math anxiety - an overview and implications. Frontiers in Psychology, 6. https://doi.org/10.3389/fpsyg.2015.01333

Ashcraft, M. H. (2002). Math Anxiety and Its Cognitive Consequences. Current Directions in Psychological Science, 11(5), 181-185. https://doi.org/10.1111/1467-8721.00196

Ashcraft, M. H., \& Faust, M. W. (1994). Mathematics anxiety and mental arithmetic performance: An exploratory investigation. Cognition \& Emotion, 8(2), 97-125. https://doi.org/10.1080/02699939408408931

Ashcraft, M. H., \& Moore, A. M. (2009). Mathematics anxiety and the affective drop in performance. Journal of Psychoeducational Assessment, 27(3), 197-205. https://doi.org/10.1177/0734282908330580

Ashcraft, M. H., \& Ridley, K. S. (2005). Math anxiety and its cognitive consequences: A tutorial review. In J. I. D. Campbell (Ed.), Handbook of Mathematical Cognition (pp. 315-327). New York: Psychology Press.

Bai, H. (2011). Cross-validating a bidimensional mathematics anxiety scale. Assessment, 18(1), 115122. https://doi.org/10.1177/1073191110364312

Bieg, M., Goetz, T., Wolter, I., \& Hall, N. C. (2015). Gender stereotype endorsement differentially predicts girls' and boys' trait-state discrepancy in math anxiety. Frontiers in Psychology, 6(September), 1-8. https://doi.org/10.3389/fpsyg.2015.01404

Brown, J. L., \& Sifuentes, L. M. (2016). Validation Study of the Abbreviated Math Anxiety Scale: Spanish Adaptation. Journal of Curriculum and Teaching, 5(2), 76-82. 
https://doi.org/10.5430/jct.v5n2p76

Calvo, M. G., \& Eysenck, M. W. (1992). Anxiety and Performance: The Processing Efficiency Theory. Cognition and Emotion, 6(6), 409-434. https://doi.org/10.1080/02699939208409696

Carey, E., Devine, A., Hill, F., \& Szúcs, D. (2017). Differentiating anxiety forms and their role in academic performance from primary to secondary school. Plos One, 12(3), e0174418. https://doi.org/10.1371/journal.pone.0174418

Carey, E., Hill, F., Devine, A., \& Szúcs, D. (2017). The modified abbreviated math anxiety scale: A valid and reliable instrument for use with children. Frontiers in Psychology, 8(JAN), 1-13. https://doi.org/10.3389/fpsyg.2017.00011

Caviola, S., Primi, C., Chiesi, F., \& Mammarella, I. C. (2017). Psychometric properties of the Abbreviated Math Anxiety Scale (AMAS) in Italian primary school children. Learning and Individual Differences, 55, 174-182. https://doi.org/10.1016/j.lindif.2017.03.006

Chang, H., \& Beilock, S. L. (2016). The math anxiety-math performance link and its relation to individual and environmental factors: A review of current behavioral and psychophysiological research. Current Opinion in Behavioral Sciences, 10, 33-38.

https://doi.org/10.1016/j.cobeha.2016.04.011

Cipora, K., Szczygiel, M., Willmes, K., \& Nuerk, H.-C. (2015). Math anxiety assessment with the Abbreviated Math Anxiety Scale: Applicability and usefulness: Insights from the polish adaptation. Frontiers in Psychology, 6(NOV). https://doi.org/10.3389/fpsyg.2015.01833

Cipora, K., Willmes, K., Szwarc, A., \& Nuerk, H.-C. (2017). Norms and validation of the online and paper-and-pencil versions of the Abbreviated Math Anxiety Scale (AMAS) for Polish adolescents and adults. Journal of Numerical Cognition, 3(3), 667-693. https://doi.org/10.5964/jnc.v3i3.121

Devine, A., Fawcett, K., Szűcs, D., \& Dowker, A. (2012). Gender differences in mathematics anxiety and the relation to mathematics performance while controlling for test anxiety. Behavioral and 
Brain Functions, 8(1), 33. https://doi.org/10.1186/1744-9081-8-33

Dew, K. H., Galassi, J. P., \& Galassi, M. D. (1984). Math anxiety: Relation with situational test anxiety, performance, physiological arousal, and math avoidance behavior. Journal of Counseling Psychology, 31(4), 580-583. https://doi.org/10.1037/0022-0167.31.4.580

Dietrich, J. F., Huber, S., Moeller, K., \& Klein, E. (2015). The influence of math anxiety on symbolic and non-symbolic magnitude processing. Frontiers in Psychology, 6(OCT), 1-10. https://doi.org/10.3389/fpsyg.2015.01621

Doumas, M., Morsanyi, K., \& Young, W. R. (2018). Cognitively and socially induced stress affects postural control. Experimental Brain Research, 236(1), 305-314. https://doi.org/10.1007/s00221-017-5128-8

Dowker, A., Sarkar, A., \& Looi, C. Y. (2016). Mathematics anxiety: What have we learned in 60 years? Frontiers in Psychology, 7(APR). https://doi.org/10.3389/fpsyg.2016.00508

Dreger, R. M., \& Aiken, Lewis R., J. (1957). The identification of number anxiety in a college population. Journal of Educational Psychology, 48(6), 344-351. https://doi.org/10.1037/h0045894

Eden, C., Heine, A., \& Jacobs, A. M. (2013). Mathematics Anxiety and Its Development in the Course of Formal Schooling-A Review. Psychology, 4(6A2), 27-35. https://doi.org/10.4236/psych.2013.46A2005

Endler, N. S., \& Kocovski, N. L. (2001). State and trait anxiety revisited. Journal of Anxiety Disorders, 15(3), 231-245. https://doi.org/Doi: 10.1016/s0887-6185(01)00060-3

Faust, M. W., Ashcraft, M. H., \& Fleck, D. E. (1996). Mathematics Anxiety Effects in Simple and Complex Addition. Mathematical Cognition, 2(1), 25-62. https://doi.org/10.1080/135467996387534

Ferguson, A. M., Maloney, E. A., Fugelsang, J., \& Risko, E. F. (2015). On the relation between math 
and spatial ability: The case of math anxiety. Learning and Individual Differences, 39, 1-12. https://doi.org/10.1016/j.lindif.2015.02.007

Foley, A. E., Herts, J. B., Borgonovi, F., Guerriero, S., Levine, S. C., \& Beilock, S. L. (2017). The Math Anxiety-Performance Link: A Global Phenomenon. Current Directions in Psychological Science, 26(1), 52-58. https://doi.org/10.1177/0963721416672463

Georges, C., Hoffmann, D., \& Schiltz, C. (2016). How math anxiety relates to number-space associations. Frontiers in Psychology, 7(SEP), 1-15. https://doi.org/10.3389/fpsyg.2016.01401

Harari, R. R., Vukovic, R. K., \& Bailey, S. P. (2013). Mathematics anxiety in young children: An exploratory study. Journal of Experimental Education, 81(4), 538-555. https://doi.org/10.1080/00220973.2012.727888

Hart, S., Logan, J., Thompson, L., Kovas, Y., McLoughlin, G., \& Petrill, S. (2015). A latent profile analysis of mathematics achievement, numerosity and mathematics anxiety in twins. Journal of Educational Psychology, 108(2), 181-193.

Hartwright, C. E., Looi, C. Y., Sella, F., Inuggi, A., Santos, F. H., González-Salinas, C., ... Fuentes, Louis, J. (2018). The Neurocognitive Architecture of Individual Differences in Math Anxiety in Typical Children. Scientific Reports, 8. https://doi.org/10.1038/s41598-018-26912-5

Hickendorff, M., Edelsbrunner, P. A., McMullen, J., Schneider, M., \& Trezise, K. (2018). Informative tools for characterizing individual differences in learning: Latent class, latent profile, and latent transition analysis. Learning and Individual Differences, 66, 4-15. https://doi.org/10.1016/j.lindif.2017.11.001

Ho, H.-Z., Senturk, D., Lam, A. G., Zimmer, J. M., Hong, S., Okamoto, Y., ... Wang, C.-P. (2000). The Affective and Cognitive Dimensions of Math Anxiety: A Cross-National Study. Source: Journal for Research in Mathematics Education, 31(3), 362-379. https://doi.org/10.2307/749811

Hopko, D. R. (2003). Confirmatory factor analysis of the math anxiety rating scale-revised. 
Educational and Psychological Measurement, 63(2), 336-351.

https://doi.org/10.1177/0013164402251041

Hopko, D. R., Mahadevan, R., Bare, R. L., \& Hunt, M. K. (2003). The abbreviated math anxiety scale (AMAS) construction, validity, and reliability. Assessment, 10(2), 178-182.

https://doi.org/10.1177/1073191103252351

Hopko, D. R., McNeil, D. W., Gleason, P. J., \& Rabalais, A. E. (2002). The emotional stroop paradigm: Performance as a function of stimulus properties and self-reported mathematics anxiety. Cognitive Therapy and Research, 26(2), 157-166. https://doi.org/10.1023/A:1014578218041

Hopko, D. R., McNeil, D. W., Lejuez, C. W., Ashcraft, M. H., Eifert, G. H., \& Riel, J. (2003). The effects of anxious responding on mental arithmetic and lexical decision task performance. Journal of Anxiety Disorders, 17(6), 647-665. https://doi.org/10.1016/S0887-6185(02)00240-2

Hunt, T. E., Clark-Carter, D., \& Sheffield, D. (2011). The development and part validation of a U.K. scale for mathematics anxiety. Journal of Psychoeducational Assessment, 29(5), 455-466. https://doi.org/10.1177/0734282910392892

Jameson, M. M. (2013). The Development and Validation of the Children's Anxiety in Math Scale. Journal of Psychoeducational Assessment, 31(4), 391-395. https://doi.org/10.1177/0734282912470131

Jones, W. J., Childers, T. L., \& Jiang, Y. (2012). The shopping brain: Math anxiety modulates brain responses to buying decisions. Biological Psychology, 89(1), 201-213. https://doi.org/10.1016/j.biopsycho.2011.10.011

Justicia-Galiano, M. J., Martín-Puga, M. E., Linares, R., \& Pelegrina, S. (2017). Math anxiety and math performance in children: The mediating roles of working memory and math self-concept. British Journal of Educational Psychology, 87(4), 573-589. https://doi.org/10.1111/bjep.12165

Kazelskis, R. (1998). Some Dimensions of Mathematics Anxiety: A Factor Analysis Across Instruments. 
Educational and Psychological Measurement, 58(4), 623-633.

https://doi.org/10.1177/0013164498058004006

Klados, M. A., Pandria, N., Micheloyannis, S., Margulies, D., \& Bamidis, P. D. (2017). Math anxiety: Brain cortical network changes in anticipation of doing mathematics. International Journal of Psychophysiology, 122, 24-31. https://doi.org/10.1016/J.IJPSYCHO.2017.05.003

Klados, M. A., Simos, P., Micheloyannis, S., Margulies, D., \& Bamidis, P. D. (2015). ERP measures of math anxiety: how math anxiety affects working memory and mental calculation tasks? Frontiers in Behavioral Neuroscience, 9(October), 1-9. https://doi.org/10.3389/fnbeh.2015.00282

Krinzinger, H., Kaufmann, L., Dowker, A., Thomas, G., Graf, M., Nuerk, H.-C., \& Willmes, K. (2007). Deutschsprachige Version des Fragebogens für Rechenangst (FRA) für 6- bis 9-jährige Kinder. Zeitschrift Für Kinder- Und Jugendpsychiatrie Und Psychotherapie, 35(5), 341-351. https://doi.org/10.1024/1422-4917.35.5.341

Krinzinger, H., Kaufmann, L., \& Willmes, K. (2009). Math anxiety and math ability in early primary school years. Journal of Psychoeducational Assessment, 27(3), 206-225. https://doi.org/10.1177/0734282908330583

Lee, J. (2009). Universals and specifics of math self-concept, math self-efficacy, and math anxiety across 41 PISA 2003 participating countries. Learning and Individual Differences, 19(3), 355365. https://doi.org/10.1016/j.lindif.2008.10.009

Lyons, I. M., \& Beilock, S. L. (2012a). Mathematics anxiety: Separating the math from the anxiety. Cerebral Cortex, 22(9), 2102-2110. https://doi.org/10.1093/cercor/bhr289

Lyons, I. M., \& Beilock, S. L. (2012b). When Math Hurts: Math Anxiety Predicts Pain Network Activation in Anticipation of Doing Math. PLOS ONE, 7(10). https://doi.org/10.1371/journal.pone.0048076 
Ma, X., \& Xu, J. (2004). The causal ordering of mathematics anxiety and mathematics achievement: A longitudinal panel analysis. Journal of Adolescence, 27(2), 165-179. https://doi.org/10.1016/j.adolescence.2003.11.003

Mammarella, I. C., Donolato, E., Caviola, S., \& Giofrè, D. (2018). Anxiety profiles and protective factors: A latent profile analysis in children. Personality and Individual Differences, 124, 201208. https://doi.org/10.1016/j.paid.2017.12.017

Mattarella-Micke, A., Mateo, J., Kozak, M. N., Foster, K., \& Beilock, S. L. (2011). Choke or Thrive? The Relation Between Salivary Cortisol and Math Performance Depends on Individual Differences in Working Memory and Math-Anxiety. Emotion, 11(4), 1000-1005. https://doi.org/10.1037/a0023224

Morsanyi, K., Mammarella, I. C., Szücs, D., Tomasetto, C., Primi, C., \& Maloney, E. A. (2016). Editorial: Mathematical and statistics anxiety: Educational, social, developmental and cognitive perspectives. Frontiers in Psychology, 7(JUL), 1-4. https://doi.org/10.3389/fpsyg.2016.01083

Mulhern, F., \& Rae, G. (1998). Development of a Shortened form of the Fennema-Sherman Mathematics Attitudes Scales. Educational and Psychological Measurement, 58(2), 295-306. https://doi.org/10.1177/0013164498058002012

Necka, E. A., Sokolowski, H. M., \& Lyons, I. M. (2015). The role of self-math overlap in understanding math anxiety and the relation between math anxiety and performance. Frontiers in Psychology, 6(OCT), 1-12. https://doi.org/10.3389/fpsyg.2015.01543

Núñez-Peña, M. I., Guilera, G., \& Suárez-Pellicioni, M. (2014). The Single-Item Math Anxiety Scale: An Alternative Way of Measuring Mathematical Anxiety. Journal of Psychoeducational Assessment, 32(4), 306-317. https://doi.org/10.1177/0734282913508528

Núñez-Peña, M. I., \& Suárez-Pellicioni, M. (2014). Less precise representation of numerical magnitude in high math-anxious individuals: An ERP study of the size and distance effects. Biological Psychology, 103, 176-183. https://doi.org/10.1016/j.biopsycho.2014.09.004 
OECD. (2013). PISA 2012 Results: Ready to Learn: Students' Engagement, Drive and Self-Beliefs (Volume III). Pisa (Vol. III). https://doi.org/10.1787/9789264201170-en

Osborne, J. W. (2006). Gender, Stereotype Threat, and Anxiety: Psychophysiological and cognitive evidence. Electronic Journal of Research in Educational Psychology, 4, 109-138.

Pizzie, R. G., \& Kraemer, D. J. M. (2017). Brain and Cognition Avoiding math on a rapid timescale : Emotional responsivity and anxious attention in math anxiety. Brain and Cognition, 118(August), 100-107. https://doi.org/10.1016/j.bandc.2017.08.004

Pletzer, B., Kronbichler, M., Nuerk, H.-C., \& Kerschbaum, H. H. (2015). Mathematics anxiety reduces default mode network deactivation in response to numerical tasks. Frontiers in Human Neuroscience, 9(April), 1-12. https://doi.org/10.3389/fnhum.2015.00202

Pletzer, B., Wood, G., Moeller, K., Nuerk, H. C., \& Kerschbaum, H. H. (2010). Predictors of performance in a real-life statistics examination depend on the individual cortisol profile. Biological Psychology, 85(3), 410-416. https://doi.org/10.1016/j.biopsycho.2010.08.015

Pletzer, B., Wood, G., Scherndl, T., Kerschbaum, H. H., \& Nuerk, H.-C. (2016). Components of mathematics anxiety: Factor modeling of the MARS30-brief. Frontiers in Psychology, 7(FEB), 114. https://doi.org/10.3389/fpsyg.2016.00091

Primi, C., Busdraghi, C., Tomasetto, C., Morsanyi, K., \& Chiesi, F. (2014). Measuring math anxiety in Italian college and high school students: Validity, reliability and gender invariance of the Abbreviated Math Anxiety Scale (AMAS). Learning and Individual Differences, 34, 51-56. https://doi.org/10.1016/j.lindif.2014.05.012

Ramirez, G., Gunderson, E. A., Levine, S. C., \& Beilock, S. L. (2013). Math Anxiety, Working Memory, and Math Achievement in Early Elementary School. Journal of Cognition and Development, 14(2), 187-202. https://doi.org/10.1080/15248372.2012.664593

Reips, U.-D. (2002). Standards for Internet-based experimenting. Experimental Psychology, 49(4), 
243-256. https://doi.org/10.1026//1618-3169.49.4.243

Richardson, F. C., \& Suinn, R. M. (1972). The Mathematics Anxiety Rating Scale: Psychometric data. Journal of Counseling Psychology, 19(6), 551-554. https://doi.org/10.1037/h0033456

Roos, A.-L., Bieg, M., Goetz, T., Frenzel, A. C., Taxer, J., \& Zeidner, M. (2015). Experiencing more mathematics anxiety than expected? Contrasting trait and state anxiety in high achieving students. High Ability Studies, 26(2), 245-258.

https://doi.org/10.1080/13598139.2015.1095078

Sacks, O. (1985). The Man Who Mistook His Wife for a Hat and Other Clinical Tales. New York: Summit Books.

Salvia, E., Guillot, A., Collet, C., Ea, C., Motrice, P., Bernard, U. C., ... France, I. U. De. (2013). The Effects of Mental Arithmetic Strain on Behavioral and Physiological Responses, 27(4), 173-184. https://doi.org/10.1027/0269-8803/a000102

Sarkar, A., Dowker, A., \& Cohen Kadosh, R. (2014). Cognitive Enhancement or Cognitive Cost: TraitSpecific Outcomes of Brain Stimulation in the Case of Mathematics Anxiety. Journal of Neuroscience, 34(50), 16605-16610. https://doi.org/10.1523/JNEUROSCI.3129-14.2014

Schillinger, F. L., Vogel, S. E., Diedrich, J., \& Grabner, R. H. (2018). Math anxiety, intelligence, and performance in mathematics: Insights from the German adaptation of the Abbreviated Math Anxiety Scale (AMAS-G). Learning and Individual Differences, 61, 109-119. https://doi.org/10.1016/J.LINDIF.2017.11.014

Suárez-Pellicioni, M., Núñez-Peña, M. I., \& Colomé, A. (2013a). Mathematical anxiety effects on simple arithmetic processing efficiency: An event-related potential study. Biological Psychology, 94(3), 517-526. https://doi.org/10.1016/j.biopsycho.2013.09.012

Suárez-Pellicioni, M., Núñez-Peña, M. I., \& Colomé, À. (2013b). Abnormal error monitoring in mathanxious individuals: Evidence from error-related brain potentials. PLOS ONE, 8(11), 1-17. 
https://doi.org/10.1371/journal.pone.0081143

Suárez-Pellicioni, M., Núñez-Peña, M. I., \& Colomé, À. (2014). Reactive recruitment of attentional control in math anxiety: An ERP study of numeric conflict monitoring and adaptation. PLOS ONE, 9(6). https://doi.org/10.1371/journal.pone.0099579

Suinn, R. M., \& Edwards, R. (1982). The measurement of mathematics anxiety: The mathematics anxiety rating scale for adolescents-MARS-A. Journal of Clinical Psychology, 38(3), 576-580. https://doi.org/10.1002/1097-4679(198207)38:3<576::AID-JCLP2270380317>3.0.CO;2-V

Suinn, R. M., Taylor, S., \& Edwards, R. W. (1988). Suinn Mathematics Anxiety Rating Scale for Elementary School Students (MARS-E): Psychometric and Normative Data. Educational and Psychological Measurement, 48(4), 979-986. https://doi.org/10.1177/0013164488484013

Thomas, G., \& Dowker, A. (2000). Mathematics anxiety and related factors in young children. In Paper presented at British Psychological Society Developmental Section Conference. Bristol, UK.

Trezise, K., \& Reeve, R. A. (2018). Patterns of anxiety in algebraic problem solving: A three-step latent variable analysis. Learning and Individual Differences, 66(February), 78-91. https://doi.org/10.1016/j.lindif.2018.02.007

Vahedi, S., \& Farrokhi, F. (2011). A confirmatory factor analysis of the structure of abbreviated math anxiety scale. Iranian Journal of Psychiatry, 6(2), 47-53.

Wang, Z., Lukowski, S. L., Hart, S. A., Lyons, I. M., Thompson, L. A., Kovas, Y., ... Petrill, S. A. (2015). Is Math Anxiety Always Bad for Math Learning? The Role of Math Motivation. Psychological Science, 26(12), 1863-1876. https://doi.org/10.1177/0956797615602471

Wang, Z., Shakeshaft, N., Schofield, K., \& Malanchini, M. (2018). Anxiety is not enough to drive me away: A latent profile analysis on math anxiety and math motivation. PLOS ONE, 13(2), 1-16. https://doi.org/10.1371/journal.pone.0192072

Wigfield, A., \& Meece, J. L. (1988). Math anxiety in elementary and secondary school students. 
Journal of Educational Psychology, 80(2), 210-216. https://doi.org/10.1037/0022-

0663.80.2.210

Wu, S. S., Barth, M., Amin, H., Malcarne, V., \& Menon, V. (2012). Math anxiety in second and third graders and its relation to mathematics achievement. Frontiers in Psychology, 3(JUN), 1-11. https://doi.org/10.3389/fpsyg.2012.00162

Yánez-Marquina, L., \& Villardón-Gallego, L. (2017). Math anxiety, a hierarchical construct: Development and validation of the Scale for Assessing Math Anxiety in Secondary education. Ansiedad y Estrés, 23, 59-65. https://doi.org/10.1016/j.anyes.2017.10.001

Young, C. B., Wu, S. S., \& Menon, V. (2012). The Neurodevelopmental Basis of Math Anxiety. Psychological Science, 23(5), 492-501. https://doi.org/10.1177/0956797611429134 